\title{
Voluminous Goiters in Surgery B of Chu of Point G: Diagnostic Aspects
}

\author{
S. Diallo ${ }^{1 *}$, O. Sacko ${ }^{2}$, L. Soumaréé, M. Coulibaly' ${ }^{1}$, A. Kanté ${ }^{3}$, B. Coulibaly ${ }^{1}$, B. Togola ${ }^{1}$, B. Bengaly ${ }^{1}$, \\ D. Ouattara1, S. Sanogo'1, J. Saye1, C. A. S. Touré1, S. Koumaré2, M. Camara², S. Keita ${ }^{2}$, M. Sissoko², \\ D. Traoré1, N. Ongoiba ${ }^{1}$
}

${ }^{1}$ Service of Surgery B of CHU Point G, Bamako, Mali

${ }^{2}$ Service of Surgery A of CHU Point G, Bamako, Mali

${ }^{3}$ Laboratory of Anatomy of the Faculty of Medicine and Odontostomatology, Bamako, Mali

Email: ^diallosk3@yahoo.fr

How to cite this paper: Diallo, S., Sacko, O., Soumaré, L., Coulibaly, M., Kanté, A., Coulibaly, B., Togola, B., Bengaly, B., Ouattara, D., Sanogo, S., Saye, J., Touré, C.A.S., Koumaré, S., Camara, M., Keita, S., Sissoko, M., Traoré, D. and Ongoiba, N. (2019) Voluminous Goiters in Surgery B of Chu of Point G: Diagnostic Aspects. Surgical Science, 10, 310-315.

https://doi.org/10.4236/ss.2019.109034

Received: August 7, 2019

Accepted: September 15, 2019

Published: September 18, 2019

Copyright $\odot 2019$ by author(s) and Scientific Research Publishing Inc. This work is licensed under the Creative Commons Attribution-NonCommercial International License (CC BY-NC 4.0). http://creativecommons.org/licenses/by-nc/4.0/ (c) (i) (8) Open Access

\begin{abstract}
Purpose: To describe the aspects of the positive diagnosis of large goiters. Patients and Methods: We conducted a retrospective and prospective study including 115 patients from January, 2009 till December, 2014 (6 years) in Central Hospital of University of Point G in Bamako (Mali). The diagnosis of large goiters was based on the measurements of the anterior neck swelling. Thus large goiter was defined as any goiter including the height or width was greater than or equal to $10 \mathrm{~cm}$ (centimeters). Results: We operated 115 cases of large goiters on 760 goiters operated either $15.1 \%$. The average age of patients was 44, 43 years $\pm 14,3$ with extremes of 9 and 80 years. There was 101 women (87.8\%) and 14 men (12.2\%) with a sex ratio of 7.2 in favor of women. The signs of compression were dyspnea in $40 \%$ of cases (46/115), dysphonia in $13.0 \%(15 / 115)$, and dysphagia in $8.6 \%$ (10/115). The average height of goiter was $12.1 \mathrm{~cm} \pm 3.5 \mathrm{~cm}$ with extremes of 10 and $29 \mathrm{~cm}$ and the average width was $14.4 \mathrm{~cm} \pm 5.4 \mathrm{~cm}$ with extremes of 10 and $32 \mathrm{~cm}$. Thyroid ultrasound found large goiters multinodular in $100 \%$. Cervical radiography found the tracheal deviation in $48.2 \%$ (42/87), tracheal compression in $20.6 \%$ (18/87), plunging goiters in $11.5 \%$ (10/87). Cytology found a benign goiter in $97.4 \%$ of cases (112/115), malignant (thyroid cancer) in $2.6 \%$ of cases (3/115). Conclusion: Diagnosis of large goiters was based on the measurement of the swelling in our context. The signs of compression are the severity of this condition.
\end{abstract}

\section{Keywords}

Voluminous Goiters, Thyroid, Diagnosis 


\section{Introduction}

Large goiters are frequent in endemic areas because of deficiency in iodine [1].

Gardiner 1995 [2] describes 64 large goiters operated on a set of 474 goiters or 14\%, Tahsin, C. in Turquie 2004 [3] conducted a study on 11 large goiters operated on a set of 200 goiters or 55.5\%, Chohaill in Maroc 2002 [4] described 83 large goiters operated on a set of 225 goiters or $36.8 \%$, Talla, A. in Dakar 2001 [5] described 27 large goiters operated on a set of 494 goiters or $5.46 \%$.

According to the WHO, the goiter is defined as being a palpable thyroid which the side lobes have a volume greater than the size of the distal phalanx of the thumb of the person examined and large goiter is one that is visible from a distance (stage 3) [6]. In a study conducted by Gardiner in RoyaumeU$\mathrm{ni}$ in 1995, it was classified as large goiter all goiter weighing more than $100 \mathrm{~g}$ in post operative [2]. Lack of specific study on large goiters, we took as a definition in this study all goiter whose height and/or width is greater than or equal to $10 \mathrm{~cm}$. The definition of large goiter based on the remote goiter's view lacks precision, especially in terms of distance. The one based on the weight of the goiter post-operative does not allow a pre-operative diagnosis. We took a definition based on the measurements of the goiter (height, width) for on the one hand accuracy and on the other hand the possibility of pre-operative diagnosis of goiter.

We wanted to do this study in order to describe the diagnostic elements of large goiters.

\section{Patients and Methods}

We conducted a retrospective and prospective study including 115 patients from 2009 till 2014 (6 years) in the Service of surgery B of the CHU of Point G. Large (voluminous) goiter was defined as any goiter including the height and or width was greater than or equal to $10 \mathrm{~cm}$. We have included in this study all goiters operated with a height or width greater than or equal to $10 \mathrm{~cm}$ in the Service of surgery B of CHU of Point G. The goiters operated with a height less than $10 \mathrm{~cm}$ and a width less than $10 \mathrm{~cm}$ were not included. Diagnosis of large goiters was based on the measurements of the swelling. The studied parameters were epidemiological and sociodemographic data, clinical aspects (signs of compression, measurements) and paraclinical aspects (ultrasound, radiology, biology, cytology).

Data processing and analysis was done on the Microsoft Windows software version 2007, SPSS 12.0 for Windows. The probability test used was Chi2 with a threshold of meaning $\mathrm{p}<0.05$.

\section{Results}

For 6 years the Service of surgery B has identified 115 large goiters on 760 operated goiters either $15.1 \%$. Also large goiters accounted for 5.5\% of all surgical interventions (115/2107) in the service. 
The average age of patients was 44,43 years $\pm 14,3$ with extremes of 9 and 80 years.

There was 1 female child who was 9 years old. In this study there was 101 women $(87.8 \%)$ and 14 men (12.2\%) with a sex ratio of 7.2 in favor of women. Large anterior neck swelling was present in $100 \%$ of patients. The signs of compression were dyspnea in $40 \%$ of cases (46/115), dysphonia in $13 \%$ (15/115), and dysphagia in $8.6 \%(10 / 115)$. There was no sign of compression in $47 \%$ of cases (54/115).

The average height of goiter was $12.1 \mathrm{~cm} \pm 3.5 \mathrm{~cm}$ with extremes of 10 and 29 $\mathrm{cm}$ and the average width was $14.4 \mathrm{~cm} \pm 5.4 \mathrm{~cm}$ with extremes of 10 and $32 \mathrm{~cm}$.

The height of swelling (goiter) was less than $15 \mathrm{~cm}$ at $79.1 \%$ of patients $(91 / 115)$ (Table 1). The width of swelling was less than $15 \mathrm{~cm}$ at $69.6 \%$ of patients $(80 / 115)$ (Table 2). Also the cervical perimeter of swelling was greater than $40 \mathrm{~cm}$ at $51.3 \%$ of patients (59/115) (Table 3$)$.

Thyroid ultrasound found large goiters multinodular in $100 \%$ of cases, bilateral in $76.5 \%$ of cases (88/115), unilateral in $23.5 \%$ (27/115). Cervical radiography front and profile found the tracheal deviation in $48.2 \%(42 / 87)$, tracheal compression in $20.6 \%$ (18/87), calcifications in $11.5 \%(10 / 87)$, plunging goiter in $11.5 \%(10 / 87)$. The hormonal dosage (tetra iodothyronine, and thyroid stimulating hormone) has been achieved in all patients. It was of goiters in hyperthyroidism in $21.7 \%$ of cases (25/115), goiters in euthyroidism in $78.3 \%$ of the cases

Table 1. Distribution of the patients according to the height of the swelling.

\begin{tabular}{ccc}
\hline Height swelling & Effective & Percentage \\
\hline$<15 \mathrm{~cm}$ & 91 & 79.1 \\
$15<\mathrm{H}<20$ & 13 & 11.3 \\
$\mathrm{H}>20 \mathrm{~cm}$ & 11 & 9.6 \\
Total & 115 & 100 \\
\hline
\end{tabular}

Table 2. Distribution of the patients according to the width of the swelling.

\begin{tabular}{ccc}
\hline Width swelling $(\mathrm{cm})$ & Effective & Percentage \\
\hline $\mathrm{L}<15$ & 80 & 69.6 \\
$15<\mathrm{L}<20$ & 18 & 15.6 \\
$\mathrm{~L}>20$ & 17 & 14.8 \\
Total & 115 & 100 \\
\hline
\end{tabular}

Table 3. Distribution of the patients according to the cervical perimeter (around the neck).

\begin{tabular}{ccc}
\hline Cervical perimeter $(\mathrm{cm})$ & Effective & Percentage \\
\hline$<30$ & 2 & 1.7 \\
$30<\mathrm{PC}<40$ & 54 & 47 \\
$>40$ & 59 & 51.3 \\
Total & 115 & 100 \\
\hline
\end{tabular}


(90/115). There is no case of hypothyroidism. Cytology found a benign goiter in 97.4\% (112/115) cases, malignant (thyroid cancer) in 2.6\% (3/115).

We proceeded of surgical treatment in $100 \%$ of cases $(115 / 115)$.

The postoperative suites were simple in $81.7 \%$ (94/115), complicated in $18.3 \%$ (21/115).

\section{Discussion}

In terms of methodology, it was a retrospective and prospective study on 115 cases of large goiter during a period of 6 years, from 2009 till 2014.

The frequency of large goiters operated was $15.1 \%$. This same trend was found by Gardiner in RoyaumeUni ( $p=0.812)$ [2]. By against Tahsin, C. in Turquie, Chohaill, H. in Maroc and Talla, A. in Dakar [3] [4] [5] were reported respectively higher frequencies $(\mathrm{p}<0.05)$. This difference could be explained by the fact that in their studies large goiter was defined as any visible goiter remotely (type III according to WHO). This definition of large goiter based on the view of remote tumefaction is subjective and imprecise.

We have not observed significant difference between the average age of our patients (44, 43 years) and that of the other authors [3] [7] [8] [9].

The sex ratio in our study was 7.2 in favor of women. It was the same in other studies with (3.8 to 5.1) for women [7] [8] [9]. This female dominance could be explained by puberty, pregnancy, and childbirth.

Dyspnea was the most frequent sign of compression with $40 \%$. This rate was consistent with the data in the literature [3] [10] [11].

Dysphagia was found in $6 \%$ of cases. This rate is lower than those of Gardiner, K.R. in RoyaumeUni $(22 \%, \mathrm{p}<0.05)$, Bircha, M. in Maroc $(40 \%$; $\mathrm{p}<0.05)$ and Rim, Z. in Tunisie (30.2\%; p 0.05) [2] [10] [11]. Dysphonia was found in 13\% of the cases. Bircha, M. brought a higher rate of dysphonia $(73.2 \%$; $<<0.05)$ [10]. We believe that these differences could be explained by the fact that the studies of Bircha, M. in Maroc and Rim, Z. in Tunisia were on plunging large goiters which were more compression [10] [11].

In our study the diagnosis of large goiter was based on the measurements (height and width of the swelling) pre operative. So was called goiter all large goiter including the height or width was greater than or equal to $10 \mathrm{~cm}$. Of the 115 patients identified $79.1 \%$ had a height of less than $15 \mathrm{~cm}, 11.3 \%$ had a height between 15 and $20 \mathrm{~cm}$ and $9.6 \%$ had a height greater than $20 \mathrm{~cm}$ (Table 1). The width was less than $15 \mathrm{~cm}$ in $69.6 \%$, between 15 and $20 \mathrm{~cm}$ in $15.6 \%$ and greater than $20 \mathrm{~cm}$ in $14.8 \%$ (Table 2). Too the cervical perimeter was less than $30 \mathrm{~cm}$ in $1.7 \%$ of cases, between 30 and $40 \mathrm{~cm}$ in $47 \%$ and greater than $40 \mathrm{~cm}$ in $51.3 \%$ of the cases (Table 3). However, in studies of Gardiner in RoyaumeUni, Dyde, A.K. in Hollande and Andreas, H. in Allemagne [2] [7] [12] the diagnosis was respectively based on the weight of the thyroid in post operative and the size of the gland on ultrasound thyroid in pre operative. We believe that measurements allow to make the diagnosis of large goiter prior to the operation. They are simple, 
practical and not expensive as they are by the clinic.

Thyroid ultrasound of large goiters found multinodulargoiters in $100 \%$ of cases. This rate is not different significantly from those of Talla, A. in Dakar $(100 \%, p>0.05)$, Rim, Z. in Tunisie $(97.2 \%, p>0.05)$ and Keita, M. in Mali $(96.9 \%, \mathrm{p}=0.75)[1][11][13]$.

Cervical radiography, front and profile were conducted in 87 patients $(75.6 \%$ of cases). The deviation of the trachea was the most frequent sign with $36.5 \%$ of cases. This rate was lower than that of Gardiner, K.R. in RoyaumeUni (70\%; p < 0.05) [2]. This difference could be explained by the fact that in our study large bilateral goiters were more numerous. These bilateral goiters do less tracheal deviation. Tracheal compression was found in $15.6 \%$ of cases. We did not find difference between this rate and the Chohaill in Maroc (20.6\%; $p=0.37)$ [4], but Gardiner, K.R. brought a higher rate $(42 \% ; \mathrm{p}<0.05)$ [2]. This difference could be explained by the fact that in the study of Gardiner KR [2] cervical radiography was performed in all patients. In this study the goiter was plunging in $8.7 \%$ of cases. This rate was lower than that of Rim, Z. in Tunisie $(100 \% ; p<0.05)$ [11]. This difference could be explained by the fact that the study of Rim, Z. in Tunisie [11] covered big plunging goiters.

\section{Conclusion}

In this study we have identified 115 large goiter cases in the Service of surgery B of CHU of Point G. Large goiters are frequent in our service. Women are much more affected than men. The diagnosis of large goiters was based on the measurements of the swelling.

\section{Authorization of the Ethics Committee}

We, undersigned, authors of this article give evidence that we received the authorization of the Ethics Committee for the realization of this study.

\section{Conflicts of Interest}

The authors state that there is no conflict of interest in the publication of this article.

\section{References}

[1] Agarwal, A., Agarwal, S., Tewari, P., Gupta, S., Chand, G., Mishra, A., Agarwal, G., Verma, A.K. and Mishra, S.K. (2012) Profil clinico-pathologique, la gestion des voies respiratoires, et le résultat d'énormes goitres multinodulaires: Une expérience institutionnelle d'une région de goitre endémique. Département de chirurgie endocrinienne, Sanjay Gandhi Poster Institut universitaire des sciences médicales en Inde. World Journal of Surgery, 36, 755-760. https://doi.org/10.1007/s00268-012-1447-x

[2] Gardiner, K.R. and Russel, C.F. (1995) Thyroidectomy for Large Multinodular Colloid Goiters. Journal of the Royal College of Surgeons of Edinburgh, 40, 367-370.

[3] Tahsin, C., Tamera, K., Arzu, K., Davud, Y. and Suha, A. (2004) Total versus Sub- 
total Thyroidectomy for the Management of Benign Multinodular Goiter in an Endemic Region. ANZ Journal of Surgery, 74, 974-978. https://doi.org/10.1111/j.1445-1433.2004.03139.x

[4] Chohaill, H. (2002) Les indications chirurgicales dans la pathologie thyroïdienne. Thèse demédecine Casablanca Maroc, No. 54.

[5] Tall, A., Diouf, R., Diallo, B. and Diop, E. (2001) Importance et prise en charge des trachéo-malacies dans la chirurgie des goitres multi-hétéro-nodulaires au CHU de Dakar. Les cahiers d'oto-rhino-laryngologie. De Chirurgie Cervico-Faciale et D’audiophonologie, 36, 95-100.

[6] OMS, FAO (2003) Régime alimentaire, nutrition et prévention des maladies chroniques. Rapport d'une consultation OMS/FAO d'experts, Genève, 12, 8-11.

[7] Dyde, A.K.C., Huysmans, M.D., Annonce, R.M.M., Hermus, M.D., Frans, H.M., Corstens, M.D., Jelle, O., Barentsz, M.D., Peter de, W.C. and Kloppenborg, M.D. (1994) Les grandes goitres compressifs traités à l'iode radioactif. Pays-Bas Annals of Internal Medicine, 12110, 757-762.

[8] Haddad, L., Haddad, F.L., Bittencourt, L., Gregório, L.C., Tufik, S. and Abrahão, M. (2013) Clinical and Polysomnographic Findings of Patients with Large Goiters. Sleep and Breathing, 17, 673-678. https://doi.org/10.1007/s11325-012-0741-z

[9] Leonardo, H., Fernanda, L., Martinho, H., Lia, B., Luis, C.G., Sergio, T. and Marcio, A. (2013) Impact de la thyroïdectomie sur la lutte contre le syndrome d'apnée obstructive du sommeil chez les patients avec de grandes goitres. Universidade Federal de São Paulo-UNIFESP, São Paulo, 2, 4-6.

[10] Bricha, M. (2011) les goitres plongeants (A propos de 41 cas). Thèse de médecine Maroc, No. 60, 16-138.

[11] Rim, Z., Chafik El, A., Rim, B., Najeh, B., Semia, S. and Ghazi, B. (2011) Les gros goîtres plongeants: À propos de 43 cas. La Tunisie Medicale, 89, 860-865.

[12] Andreas, H., Andreas, O. and Manfred, B. (2011) L'efficacité d'une thérapie à l'iode radioactif unique de dose individuelle, en grande goitre en fonction du type de la maladie de la thyroïde bénigne. Médecine nucléaire, CHU de Halle (Saale) Allemagne, No. 1927.

[13] Keita, M., Diango, D., Traoré, C., Kamaté, B. and Mohamed, A. (2007) Les goitres bénins en orl aspects épidémiologiques et anatomocliniques: Etude de 97 cas. Journal Tunisien d ORL et de Chirurgie Cervico-Faciale, 18, 16-19. https://doi.org/10.4314/jtdorl.v18i1.42039 